\title{
UPAYA PENGENDALIAN KECELAKAAN KERJA DI UNIT GRANULE PT. BINA GUNA KIMIA UNGARAN SEMARANG TAHUN 2015
}

\author{
Roudlatun Naashichah' ${ }^{1)}$, Zaeni Budiono²) \\ Jurusan Kesehatan Lingkungan, Politeknik Kesehatan Kemenkes Semarang, \\ Jl.Raya Baturaden KM 12 Purwokerto, Indonesia
}

\begin{abstract}
HIRA is an early stage in risk management, which became one of the clauses in the application of OHSAS 18001. At the PT. BinaGuna Kimia Ungaran Semarang, HIRA has been applied in identifying hazards, but occupational accident still occured. The purpose of this study determine the source of hazard, potential hazard, the type of hazard, risk assessment and the efforts to control risk of occupational accident in Granule Unit at PT. BinaGuna Kimia Ungaran Semarang. The type of this study descriptive. Subjects were 9 labors with supervisor Granule Unit and the coordinator of SHE. The result of this study there are 17 sources of hazard, 28 potential hazards, and 60 types of hazard in Granule Unit. Risk hazard assessment there are 44 high risk, 14 medium risk and 2 low risk. Risk control They are technical (engineering) control, administrative and personal protective equipment. The conclusion of this study is the sources of hazard in Granule Unit at PT. BinaGuna Kimia Ungaran Semarang are derived from the materials, tools, machinery, work environment, procedural, poor housekeeping (less well goods arrangement), and unsafe behaviour. There are 28 potential hazards, and 60 types of hazard in Granule Unit. Risk hazard assessment was grouped into 3, which are high, medium and low risk. In the case, there are 44 high risk, 14 medium risk and 2 low risk. Risk control is done with 3 ways. They are technical (engineering) control, administrative and personal protective equipment.
\end{abstract}

Keywords : HIRA, Chemical

\begin{abstract}
Abstrak
HIRA merupakan tahapan awal dalam manajemen risiko, yang menjadi salah satu klausul dalam penerapan OHSAS 18001. Pada PT. Bina Guna Kimia Ungaran Semarang, HIRA sudah diterapkan dalam mengidentifikasi bahaya, akan tetapi kecelakaan kerja masih terjadi. Tujuan penelitian ini mengetahui sumber bahaya, potensi bahaya, jenis bahaya, penilaian risiko dan upaya pengendalian risiko kecelakaan kerja di Unit Granule PT. Bina Guna Kimia Ungaran Semarang. Jenis penelitian yang digunakan deskriptif. Subyek penelitian ini 9 pekerja dengan supervisor Unit Granule dan koordinator SHE. Hasil penelitian ini ada 17 sumber bahaya, 28 potensi bahaya, 60 jenis bahaya di Unit Granule. Penilaian risiko terhadap bahaya tersebut ada 44 risiko tinggi, 14 risiko sedang dan 2 risiko rendah. Pengendalian risiko dilakukan dengan pengendalian teknis (engineering), administrasi dan alat pelindung diri. Simpulan dari penelitian ini yaitu sumber bahaya di Unit GranulePT. Bina Guna Kimia Ungaran Semarang berasal dari bahan, alat, mesin, lingkungan kerja, cara kerja, dan perilaku yang tidak aman. Potensi bahaya di Unit Granuleada 28 potensi bahaya. Jenis bahaya ada 60 bahaya. Penilaian risiko terhadap bahaya tersebut ada 3 yaituhigh, medium dan low. Upaya pengendalian yang dilakukan yaitu pengendalian teknis (engineering), administrasi dan alat pelindung diri.
\end{abstract}

Kata kunci : HIRA, Kimia

\section{PENDAhUluan}

Manusia sebagai tenaga kerja selalu berhubungan dengan mesin, peralatan dan tempat kerja yang kemungkinan akan menimbulkan kecelakaan kerja. Terjadinya kecelakaan dan penyakit akibat kerja menjadi masalah yang besar bagi kelangsungan sebuah perusahaan.

Kecelakaan kerja dapat menimbulkan kerugian yang besar. Keselamatan dan Kesehatan Kerja (K3) merupakan salah satu aspek perlindungan tenaga kerja sekaligus melindungi asset perusahaan. Untuk

1) E-mail: Roudlatunnaashichah@ymail.com

2) E-mail:pakzaeni@gmail.com menjamin pelaksanaan K3 perusahaan perlu mengembangkan management risk yang didasarkan pada identifikasi bahaya dan penilaian risiko.

PT. Bina Guna Kimia merupakan perusahaan yang bergerak di bidang formulasi pestisida. Manajemen perusahaan tersebut menyadari betapa pentingnya penilaian risiko untuk mengurangi kerugian perusahaan.HIRA sudah diterapkan di PT. Bina Guna Kimia, merujuk pada Occupational Health and Safety Resource Manual. 
Unit granule merupakan salah satuUnit di PT. Bina Guna Kimia Ungaran yang memproduksi pestisida dalam bentuk butiran dan bubuk. Proses kerja, peralatan, dan bahan yang digunakan berpotensi menjadi sumber bahaya yang dapat menimbulkan kecelakaan kerja dari kategori ringan sampai berat. Aktifitas pekerjaan pada Unit Granule yang meliputi proses formulasi, filling, packaging, operator komputer, maintenance, dan forklift driver memiliki potensi bahaya yang berbeda-beda. Aktifitas proses produksi yang cukup padat di Unit ini, membuat para pekerja tidak luput dari potensi bahaya yang ada.

Berdasarkan survey pendahuluan HIRA sudah diterapkan dalam mengidentifikasi bahaya di industry pestisida, Hasil penilaian risiko di Unit Granule termasuk dalam kategori tinggi. Upaya pengendalian sudah dilakukan dengan menggunakan standar OHSAS 18001.

Tujuan penelitian ini mendeskripsikan upaya pengendalian kecelakaan kerja di Unit Granule PT. Bina Guna Kimia Ungaran Semarang.

\section{METODE}

Jenis penelitian ini merupakan penelitian deskriptif. Penulis mendeskripsikan tentang potensi bahaya, risiko pada pekerja, indentifikasi bahaya, penilaian risiko, dan pengendalian kecelakaan di Unit Granule PT. Bina Guna Kimia Ungaran.

Subyek dalam penelitian ini yaitu 9 informan utama yaitu pekerja di Unit Granule industry pestisida yang mewakili masing-masing aktifitas proses pekerjaan di unit granule. Informan triangulasi dalam penelitian ini yaitu, supervisor Unit Granule dan pihak manajemen yang diwakili oleh koordinator SHE (Safety Health and Environment).

\section{III.HASIL DAN PEMBAHASAN}

\section{Hasil}

Sumber bahaya yang ada di Unit Granule berasal dari bahan/ material: bahan aktif (bahan kimia B3), surfactant dan pewarna dalam proses produksi furadan di Unit Granule. Alat: cutter, shiping cartoon, computer, kursi, martil, borlistrik, gerinda, meteran, penggaris siku, tang, obeng, kunci pas, kunci inggris, kunci pas dalam proses perbaikan ataupun perawatan dan perbaikan mesin. Mesin: lift, dumping cabinet,,munson, dryer/ burner, hopper finish, forklift driver, jaringan listrik.. Lingkungan kerja: lokasi pekerjaan, suara keras dari mesin, debu, asap, iklim kerja panas dan ergonomi. Cara kerja: sikap kerja yang salah, prosedur kerja yang salah, mengangkat beban berat, perilaku yang tidak aman.

Potensi bahaya pada aktifitas pekerjaan di Unit Granule PT. Bina Guna Kimia Ungaran Semarang ditemukan 28 potensi bahaya.
Jenis bahaya pada aktifitas pekerjaan di Unit Granule PT. Bina Guna Kimia Ungaran Semarang ditemukan 60 jenis bahaya.

Penilaian resiko yang ada di Unit Granule PT. Bina Guna Kimia Ungaran didapatkan hasil 60 risiko. Risiko ekstreme tidak ada, 44 risiko tinggi, 14 risiko sedang dan 2 risiko rendah.

Upaya pengendalian risiko kecelakaan kerja yang diterapkan di Unit Granule PT. Bina Guna Kimia Ungaran Semarang yaitu: pengendalian teknis (Engineering), Administratif dan Alat Pelindung Diri.

\section{Pembahasan}

Bagian Formulasi terdapat sumber bahaya dari bahan baku yaitu; percikan material B3. Sumber bahaya lain (lingkungan fisik) muncul akibat peralatan sehingga menimbulkan suara bising dan pada lingkungan area formulasi. Pengaturan lama jam kerja telah diatur oleh perusahaan. Potensi Bahaya di bagian formulasi yaitu; paparan bahan kimia ,pekerja diwajibkan memakai APD guna melindungi tubuh dari paparan bahan kimia. Potensi bahaya (lingkungan fisik) muncul akibat peralatan mesin yang beroperasi sehingga menimbulkan suara bising dan getaran.Jenis Bahaya di bagian formulasi yaitu; gangguan pernafasan, iritasi kulit, iritasi mata, pusing, pingsan, keracunan akibat paparan bahan kimia B3. Jenis bahaya dari (lingkungan fisik) muncul akibat mesin yang beroperasi sehingga menimbulkan suara bising yaitu tuli dan terganggunya pekerjaan. Maka pekerja bagian formulasi diwajibkan mnggunakan ear plug untuk melindungi telinga dari paparan suara dengan intensitas tinggi. Penilaian Risiko seluruh bahaya yang ada di bagian formulasi ada 34 risiko bahaya. Risiko tinggi ada 24, 8 risiko sedang dan 2 risiko rendah. Upaya Pengendalian Risiko telah dilakukan oleh perusahaan dari segi engineering, yaitu pemasangan local exhauster pada area produksi dari segi administratif perusahaan juga telah melakukan upaya monitoring kualitas air sampling yang dilakukan setahun sekali, dari segi administrasi perusahaan telah menyediakan Alat Pelindung Diri (APD) berupa masker respirator, kacamata safety, sarung tangan nitril, tyvex, dan penggunaan celmek.

Bagian Filling terdapat sumber bahaya dari proses pengisian produk yaitu; percikan material B3. Potensi bahaya akibat bahan baku yang digunakan pada proses aktifitas pekerjaannya yaitu; paparan bahan kimia (inhalasi, adsorbsi kulit, terpercik mengenai mata dan tertelan). Pekerja diwajibkan memakai APD guna melindungi tubuh dari paparan bahan kimia saat melakukan formulasi berupa masker. PenilaianRisiko dibagian formulasi Unit Granule, didapatkan hasil jumlah seluruh bahaya yang ada di bagian formulasi ada 6 risiko bahaya. Risiko tinggi ada 6. Upaya Pengendalian Risiko percikan bahan kimia telah dilakukan oleh perusahaan dari segi engineering, yaitu pemasangan local exhauster pada area produksi dari segi administratif perusahaan juga telah 
melakukan upaya monitoring kualitas air sampling yang dilakukan setahun sekali, dari segi administrasi perusahaan telah menyediakan Alat Pelindung Diri (APD) berupa masker respirator, kacamata safety, sarung tangan nitril, tyvex, dan penggunaan celmek pada saat pekerjaan formulasi pestisida.

Bagian Packing terdapat sumber bahaya berupa faktor ergonomi (posisi kerja) yang dapat menimbulkan strain terdapat pada sikap kerja duduk saat pengepakan produk, sikap kerja berdiri saat menata produk. Potensi Bahaya strain (faktor ergonomi) juga dapat terjadi karena sikap kerja duduk yang salah, sebaiknya diberikan training ergonomi dan penyediaan kursi yang ergonomis sesuai tubuh pekerja. Jenis Bahaya akibat posisi kerja duduk juga dapat menimbulkan nyeri otot dan nyeri punggung, Pekerja helper sebaiknya disediakan kursi yang ergonomis agar pekerja nyaman dan tidak mudah lelah. PenilaianRisiko di bagian packing didapatkan hasil jumlah seluruh bahaya yang ada di bagian formulasi ada 2 risiko bahaya sedang. Upaya Pengendalian Risiko terhadap faktor ergonomi berupa terjadinya strain, segi engineering berupa penyediaan scissors table pada pekerjaan paleting, pengendalian segi administrasi berupa pemberian training MMH (Manual Material Handling) safety training mengenai safety behavior pada pekerjadan safety training ergonomi.

Bagian Operator Komputer terdapat sumber bahaya kegiatan mengoprasikan computer yaitu monitor computer. Jam istirahat perlu diatur agar pekerja istirhat dari aktifitas di depan monitor sepanjang jam kerja. Jenis Bahaya akibat penggunaan komputer secara terus-menerus juga dapat berakibat terjadinya CVS (Computer Visual Syndrome), Pekerja diberi jam istirahat yaitu setiap shiftnya diberi waktu istirahat sekitar 10 menit sebanyak 2 kali. Penilaian Risiko mendapatkan mendapatkan skor likelihood (kemungkinan) 5, dan mendapatkan skor (severity) 2. Upaya Pengendalian Risiko pencahayaan sudah dilakukan pada perusahaan, pengendalian yang dilakukan berupa pengendalian engineering yaitu, dengan penambahan cahaya buatan (berupa penambahan lampu) dan cahaya alami (pergantian beberapa titik atap pabrik dengan fiber yang bening), sedangkan pengendalian administratif yaitu pelaksanaan monitoring illuminasi pada area kerja produksi.

Bagian Maintenance terdapat jenis kegiatan yang di dalamnya terdapat bahaya adalah perbaikan dan perawatan mesin produksi di Unit Granule. Sumber bahaya berupa: instalasi alat berat, jaringan listrik dan suara mesin yang keras. Perbaikan dan perawatan mesin harus dilakukan sesuai dengan Standard Operasional Procedure yang ada. Penggunaan peralatan perbaikan dapat berpotensi terjadinya suatu kecelakaan, seperti kaki tertimpa alat yang jatuh, tangan terjepit peralatan dan tangan tertimpa alat, kepala terantuk alat yang posisinya rendah, terkena peralatan yang tajam yang dapat mengakibatkan luka sayat .

Jenis bahaya dari kegiatan tersebut yaitu: luka berat, perdarahan, fraktur saat kaki tertimpa alat yang jatuh, electric shock, detak jantung berhenti, kerusakan otot, syaraf dan jaringan tubuh, luka bakar dan kematian karena tersengat listrik. Penilaian risiko di bagian formulasi Unit Granule, didapatkan hasil jumlah seluruh bahaya yang ada di bagian formulasi ada 11 risiko bahaya. Risiko tinggi ada 9, 2 risiko sedang. Upaya pengendalian terhadap bahaya tertimpa alat, secara administrasi telah dilakukan yaitu berupa lotto, pemasangan pelindung mesin, pembuatan SOP, dan safety training, sedangkan pengendalian dengan APD telah dilakukan safety shoes dan working gloves.Pengendalian bahaya terhadap potensi bahaya tersengat aliran listrik sudah dilakukan oleh pihak industri berupa pengendalian segi engineering berupa pemasangan listrik sesuai dengan PUIL (Peraturan Umum Instalasi Listrik).

Bagian Forklift Driver terdapat sumber bahaya pada pekerjaan forklift driver yaitu; forklift driver, jalan yang menikung, asap kendaraan yang dihasilkan forklift. Operator forklift harus kompeten dalam mengendarai forklift, operator juga harus mengetahui prosedur kerja pengoperasian forklift yang sesuai standar. Forklift hanya berjalan pada jalur forklift yang disediakan agar tidak membahayakan pekerja yang berlalu lalang.Jenis bahaya yang dapat terjadi yaitu; cidera, luka berat, cacat dan kerusakan barang karena menabrak obyek/pekerja. Operator forklift harus yang berkompeten. Pengoperasian forklift harus sesuai dengan SOP DL 3-09-009 tentang penggunaan forklift. Pada jalan menikung, forklift dapat terjatuh dan berakibat pada terjadinya cidera dan luka berat pada operator, maka operator diwajibkan memakai helmet, safety shoes, special wearpack dan safety belt. Upaya Pengendalian Risiko yaitu pemasangan cermin cembung pada tiap pertigaan Unit Granule. Upaya pengendalian dari segi administrasi yaitu berupa pembuatan SOP forklift, safety training (safety behaviour), safety riding, untuk pekerja, membunyikan klakson pada setiap perbelokkan dan SIO (Surat Ijin Operasi) bagi forklift driver Rekomendasi upaya pengendalian dari segi administrasi dapat berupa penyediaan jalur khusus berupa line forklift, line produksi, line pejalan kaki pada area Unit Granule PT. Bina Guna Kimia Ungaran Semarang. Upaya pengendalian terhadap bahaya forklift yang terjatuh telah dilakukan oleh perusahaan. Upaya pengendalian secara engineering berupa penyediaan jalur khusus forklift, pemasangan cermin cembung pada forklift. Upaya pengendalian secara administratif yaitu pembuatan SOP forklift, safety training mengenai perilaku yang aman, safety riding, line forklift dan membunyikan klakson pada belokan.

\section{IV.KESIMPULAN}


Sumber bahaya di Unit Granule PT. Bina Guna Kimia Ungaran Semarang berasal dari bahan, alat, mesin, lingkungan kerja, carakerja, dan perilaku yang tidak aman. Potensi bahaya di Unit Granule ada 28 potensi bahaya. Jenis bahaya ada 60 bahaya. Penilaian risiko terhadap bahaya tersebut ada 3 yaitu high, medium, dan low, Risiko ekstreme tidak ada, 44 risiko tinggi, 14 risiko sedang dan 2 risiko rendah.Upaya pengendalian yang dilakukan yaitu pengendalian teknis (engineering), administrasi dan alat pelindung diri.

\section{DAFTAR PUSTAKA}

Baktiansyah. Kumpulan Modul Training Integrasi OHSAS 18001 dan SMK3 Permenaker No. 5/1996.

Departemen Tenaga Kerja dan Transmigrasi RI, 2010. Data Jumlah Kasus Kecelakaan Kerja Tahun 2006-2009.

http://www.depnakertrans.go.id/

Depnaker RI ,1996, Peraturan Menteri Tenaga Kerja dan Transmigrasi No.05/MEN/1996 tentang Sistem Manajemen Keselamatan dan Kesehatan Kerja

Dinas Tenaga Kerja dan Transmigrasi Prov DIY Balai Hiperkes dan KeselamatanKerja, 2014, Pelatihan Hiperkes dan Keselamatan Kerja Bagi Teknisi Perusahaan, Yogyakarta

Dinas Tenaga Kerja dan Transmigrasi Kota Semarang Tahun 2013, Data Kecelakaan Kerja Tahun 2013. http://disnakertranskotasemarang.or.id

Kementerian Kesehatan Republik Indonesia, Data International Labour Organization (ILO) tahun 2013. http:// www.depkes.go.id

Nindya Puspiytasari, 2010, Hazard Identifikasi Dan Risk Assesment Dalam Upaya Mengurangi Tingkat Risiko Di Bagian Produksi PT. Bina Guna Kimia Ungaran Semarang, Surakarta

Peraturan Menteri Tenaga Kerjadan Transmigrasi Nomor Per.13/Men/X/2011 Tahun 2011 tentang NilaiAmbang Batas Faktor Fisika dan Faktor Kimia di Tempat Kerja

PT. Bina Guna Kimia Ungaran, 2014, HIRA Guidelines

Ramli, Soehatman, 2010a, PedomanPraktisManajemenRisikoDalamPers

Kardinan, Agus. (2000). " Pestisida Ramuan dan Aplikasinya” . PT. Penebar swadaya, Jakarta, at pektif K3 OHS Risk Management, cetakanpertama, Jakarta: Dian Rakyat

2010, Sistem Manajemen Keselamatan \& Kesehatan Kerja OSHAS 18001, cetakan kedua, Jakarta: Dian Rakyat

Sugandi, Didi. 2009. Keselamatan Kerja dan Pencegahan Kecelakaan Kerja. Hal 171-179. Dalam: SugengBudiono, Jusuf, Adriana Pusparini, Bunga Rampai Hiperkes \& KK, cetakan keempat, edisi kedua, Semarang. Badan Penerbit Universitas Diponegoro Semarang.

Suma'mur. P.K, 1981, Keselamatan Kerja Dan Pencegahan Kecelakaan, Jakarta: PT. Gunung Agung.

Suma'mur. 1996. Higiene Perusahaan dan Keselamatan Kerja. Jakarta: PT. Gunung Agung.

Suma'mur. 1989. Keselamatan Kerja dan Pencegahan Kecelakaan. Jakarta : CV. Haji Masagung.

Suma'mur. P.K, 2001, Keselamatan Kerja Dan Pencegahan Kecelakaan, Jakarta: Haji Masagung.

Tarwaka. 2008. Keselamatan dan Kesehatan Kerja. Surakarta: Harapan Press.

Tri Cahyono. 2014. Pedoman Penulisan Proposal Penelitian dan Karya Tulis Ilmiah/ Skripsi, edisi revisi ketiga, Purwokerto: Kementerian Kesehatan RI Politeknik Kesehatan Kemenkes Semarang Jurusan Kesehatan Lingkungan Purwokerto

Undang-Undang No.1 Tahun 1970 tentang Keselamatan Kerja, 2007, Himpunan Peraturan Perundang-Undangan Keselamatan dan Kesehatan Kerja. Jakarta: Depnakertrans RI.

Undang-Undang Republik Indonesia Nomor 36 tahun 2009 Tentang Kesehatan 